\title{
Espaços movediços e conflitantes na Manaus de Milton Hatoum
}

\author{
Sophia Beal
}

\begin{abstract}
RESUMO: As práticas espaciais destruidoras que tiveram lugar em Manaus durante a ditadura militar assombram Cinzas do Norte, de Milton Hatoum, de 2005. A ambientação do romance nos faz considerar como a cidade é significativa tanto para a narrativa imaginária quanto para além dos limites do romance. Descobrimos, nesse processo, uma Manaus em mudança contínua, que desafia a representação e ostenta as marcas de lutas de poder e violência histórica. A arquitetura da belle époque e a Cidade Flutuante são topoi significativos para esse jogo de interpretação espacial. A Cidade Flutuante é ao mesmo tempo um bairro real e uma metáfora que sugere um espaço vulnerável, muitas vezes eclipsado pelo peso imponente das estruturas neoclássicas da belle époque de Manaus.
\end{abstract}

PALAVRAS-CHAVE: Milton Hatoum; Cinzas do Norte; Manaus; estudos urbanos; geografia cultural

ABSTRACT: The ruinous spatial practices that took place in Manaus during the military dictatorship haunt Milton Hatoum's 2005 Cinzas do Norte. The novel's physical setting ensnares us in a game of piecing together how the city is meaningful both to the imaginary narrative and beyond the bounds of the novel. We discover, in this process, a Manaus in continuous flux, which defies representation and bears the marks of power struggles and historical violence. Manaus's belle époque architecture and the Cidade Flutuante are topoi that are significant to this game of spatial interpretation. The Cidade Flutuante is both a real neighborhood and a metaphor that suggests a vulnerable space, often eclipsed by the imposing heft of Manaus's neoclassical belle époque structures. 
Ao tornar certos espaços urbanos hipervisíveis, a literatura brasileira considera a política do espaço. Quem construiu esse complexo de habitação? O que havia aqui antes que essa rodovia fosse construída? Por que esse monumento foi feito? Ao erguer esse tipo de questionamento, a literatura brasileira nos lembra de que as cidades não são primordiais. Também não são estáticas. Fonte de negociações infindáveis, as cidades se transformam continuamente. A forma como a ficção provoca nosso engajamento emocional e sensorial nos leva a prestar mais atenção em lugares que poderíamos simplesmente aceitar. Grande parte da literatura brasileira nos conclama a imaginar como poderíamos transformar os locais onde vivemos e repensar o planejamento urbano. Além disso, a atenção cuidadosa à ambientação permite aos autores uma oportunidade para exercitarem sua verve literária através da elaboração de lugares de maneiras que matizem nossa compreensão do desenvolvimento das personagens, enredo, estado de espírito e assim por diante. Em suma, a literatura brasileira apresenta o espaço urbano como um problema político ao mesmo tempo que usa a ambientação como um recurso literário. ${ }^{1}$

Um dos mestres de fazer-nos enxergar novamente espaços é Milton Hatoum. Seu livro Cinzas do Norte, de 2005, está entre os mais aclamados romances brasileiros contemporâneos. Enquanto a maior parte da crítica literária sobre a obra de Hatoum centra-se na memória, eu argumento que o espaço, particularmente as dinâmicas de poder em torno de quem o controla e quem lhe atribui sentido, é tão importante para sua ficção. ${ }^{2}$ A cidade de Manaus e as transformações destrutivas de espaço que ali ocorreram durante a ditadura militar brasileira assombram o texto. A Manaus do romance não é um receptáculo neutro e estático em que a ação transpira. Em vez disso, a cidade exige a nossa atenção e resiste às nossas expectativas, fazendo-nos refletir de modo mais geral sobre quem controla o traçado de uma cidade e quais tipos de projetos seriam mais benéficos para a subsistência dos moradores.

1. Alguns poucos exemplos disso incluiriam O subterrâneo do Morro do Castelo (1905), de Lima Barreto, "Gaetaninho" (1927), de Antônio de Alcântara Machado, "Brasília: cinco dias" (1962), de Clarice Lispector, Paralelo 16: Brasília (1966), de José Geraldo Vieira, “A maior ponte do mundo” (1977), de Domingos Pellegrini, “A arte de andar nas ruas do Rio de Janeiro” (1992), de Rubem Fonseca, Capão Pecado (200o), de Ferréz, Eles eram muitos cavalos (2001), de Luiz Ruffato, e Becos da memória (2006), de Conceição Evaristo.

2. Como um exemplo da prevalência de memória como tema central nas análises da obra de Hatoum, ver a coleção de ensaios: CRISTO, Maria da Luz Pinheiro. Arquitetura da memória: ensaios sobre os romances Dois irmãos, Relato de um certo Oriente $e$ Cinzas do Norte, de Milton Hatoum. Manaus: Editora da Universidade Federal do Amazonas, 2007. 
Este artigo argumenta que Cinzas do Norte justapõe o peso e a austeridade das estruturas neoclássicas da belle époque manauara (1880-1910) e a vulnerabilidade e a mutabilidade da Cidade Flutuante de Manaus para refletir sobre a política e as dinâmicas de poder do espaço, relevantes para a história de Manaus e para o enredo do romance. O padrão brasileiro de forçar (direta ou indiretamente) seus cidadãos urbanos mais pobres a abandonarem suas residências em locais convenientes e se mudarem para áreas mais afastadas do centro é tão familiar e tão antigo (remonta ao século XIX) que podemos nos tornar insensíveis a ele. No entanto, somos levados a reconhecer esse tipo de violência espacial no romance de uma forma emocional e sensorial. Uma breve introdução a Hatoum e ao enredo de Cinzas do Norte vai embasar essa análise.

Manaus, longe dos centros de produção literária do Brasil, muitas vezes sequer é considerada nos círculos literários, seguindo a tendência dos acadêmicos de excluir a Amazônia em suas análises das questões consideradas mais cruciais para a cultura e ficção brasileiras. ${ }^{3}$ A extrema popularidade da ficção de Hatoum e sua aclamação pela crítica têm ajudado a Amazônia transnacional e mais especificamente o estado do Amazonas e a capital, Manaus, a ganharem visibilidade no âmbito dos estudos literários e culturais. ${ }^{4}$ Hatoum já vendeu mais de 200 mil cópias de seus livros no Brasil, e sua

3. DAlCAStagnè, Regina. “Por que precisamos de escritoras e escritores negros?”. In: silva, C. (Org.). Africanidades e relações raciais: insumos para políticas públicas na área do livro, leitura, literatura e bibliotecas no Brasil. Brasília: Fundação Cultural Palmares, 2014, pp. 66-9, p. 67. GINZBurg, Jaime. "Euclides da Cunha, a Amazônia e a barbárie”. Estudos Avançados, São Paulo, n. 24, pp. 411-6, 2010, p. 414. Disponível em: <www.revistas.usp.br/eav/article/view/10534>. Acesso em: 15 abr. 2016. Há importantes exceções a essa tendência, e vários livros são organizados em torno do tema da literatura e da Amazônia. Ver: CARvalho, João Carlos de. Amazônia revisitada: de Carvajal a Márcio Souza. Rio Branco: Editora da Universidade Federal do Acre, 2005; FOOt hardman, Francisco. A vingança da Hileia: Euclides da Cunha, a Amazônia e a literatura moderna. São Paulo: Editora da Unesp, 2009; LEÃo, Allison. Amazonas: natureza e ficção. São Paulo: Annablume, 2011; LEÃo, Allison (Org.). Amazônia: literatura e cultura. Manaus: Editora da Universidade do Estado do Amazonas, 2012; e MAligo, Pedro. Land of Metaphorical Desires: Representations of Amazonia in Brazilian Literature. New York: Peter Lang, 1998.

4. A Amazônia (que inclui Brasil, Bolívia, Colômbia, Equador, Guiana Francesa, Guiana, Peru, Suriname e Venezuela) estende-se por 7 milhões de quilômetros quadrados. Para mais informações sobre as ligações entre a localidade de grande parte da ficção de Hatoum e a aclamação da crítica, ver: AZEvEDo, Luciene. "Como se faz um autor: Milton Hatoum: 'permanência e transformação do regionalismo"'. In: DALCASTAgné, R.; MATA, A. L. N. (Orgs.). Fora do retrato: estudos de literatura brasileira contemporânea. Vinhedo: Horizonte, 2012, pp. 70-80. 
ficção foi traduzida para catorze idiomas. Ele recebeu muitos dos mais prestigiosos prêmios literários no Brasil e em Portugal, em particular para Cinzas do Norte, seu terceiro romance. O seguinte, Órfãos do Eldorado (2008), foi transformado em um longa-metragem em 2015, dirigido por Guilherme Coelho. Em busca de inspiração literária, Hatoum muitas vezes recorre às histórias de sua própria família, imigrantes libaneses estabelecidos em Manaus.

Um homem de meia-idade chamado Lavo narra Cinzas do Norte, refletindo sobre sua infância e o início da idade adulta em Manaus nas décadas de 1960 e 1970. No entanto, o que interessa a Lavo muito mais do que sua própria experiência é a família Mattoso, seus vizinhos, cuja riqueza e ruína posterior contrastam com sua própria origem humilde e subsequente mobilidade ascendente. Hatoum intercala essa narrativa principal com um texto escrito por Ranulfo, tio de Lavo, sob a forma de uma longa carta ao falecido Raimundo Mattoso (Mundo), que tinha sido colega de colégio de Lavo. A contribuição de Ranulfo interrompe a cronologia da narrativa com flashbacks que acontecem na década de 1950 em muitas das mesmas localidades, apresentando a cidade como um palimpsesto, através do qual podemos vislumbrar vestígios de práticas espaciais anteriores. O romance termina com uma carta escrita por Mundo pouco antes de sua morte prematura, no Rio de Janeiro, na década de 1980, em que reflete sobre seu tempo em Manaus. Essa polifonia bakhtiniana envolve contradições que atrasam a nossa chegada ao significado ou tornam impossível uma conclusão definitiva sobre a forma como percebemos Manaus. ${ }^{5}$ Por todo o romance, Cinzas do Norte desmistifica a dinâmica espacial de poder e nos convida a imaginar os tipos de cidade que queremos habitar.

Como as cidades produzem significado? Como a forma de nos movermos dentro das cidades produz significado? Que possibilidades existem para transformar a cidade real e suas interpretações? O romance aborda essas questões em sua apresentação dos icônicos monumentos, edifícios e ruas da belle époque no centro de Manaus. As construções podem ser interpretadas como grandiosas, nobres, sólidas e imponentes em diferentes contextos do romance, que revela as lutas de poder urbanas e valores conflitantes. Duas cenas do romance ilustram esse ponto: 1) quando o patriarca Jano

5. Bakhtin, Mikhail M. Problems of Dostoevsky's Poetics. Trad. Caryl Emerson. Minneapolis: University of Minnesota Press, 1984, p. 72. 
Mattoso leva Lavo em um passeio por sua mansão, seguido por um passeio de carro através do centro de Manaus e 2) a destruição da mansão Mattoso na década de 1970.

Quando Jano faz com Lavo um passeio por sua mansão e pelo centro de Manaus, o peso, a imposição e o conservadorismo dos objetos e edifícios refletem essas mesmas qualidades em Jano. Em uma entrevista, Hatoum, que é formado em arquitetura e presta muita atenção a ela em seus romances, descreve a estética do centro da cidade:

Nos anos 60, [Manaus] era uma cidade de 300 mil habitantes. Esbanjava um traçado arquitetônico muito europeu, praças interligadas com praças. Toda a infraestrutura urbana havia sido construída pelos ingleses entre 1885 e 1910: teatro, os monumentos, os ícones arquitetônicos, os grandes palacetes, a arquitetura neoclássica. ${ }^{6}$

Em Cinzas do Norte, Jano introduz essa Manaus de inspiração britânica, que, por sua vez, dá base à personagem. O romancista Orhan Pamuk argumenta que em um romance bem escrito o ambiente físico é "uma extensão necessária do mundo emocional, sensual e psicológico dos protagonistas", e em Cinzas do Norte isso certamente é o caso. ${ }^{7}$ No entanto, a ambientação também nos atrai para além dos limites do enredo, para que enxerguemos novamente a Manaus histórica e material.

A relação entre personagem e cenário se desenrola em uma cena que começa com Jano levando Lavo para conhecer a mansão neoclássica dos Mattoso, em 1965. O narrador é bastante detalhista aqui, replicando a deliberação com que a versão mais jovem de si mesmo observou o interior da casa:

Reparei na cristaleira [...] miniaturas de soldados e de máquinas de guerra; ao lado da vitrola, uma estante com livros e discos. Na parede oposta, a fotografia de um casarão de frente para o rio Amazonas. O luxo maior vinha de cima: um estuque antigo com figuras de liras, harpas, cavaletes e pincéis. Fiquei observando o teto até ouvir a voz de Jano:

6. наточм, Milton. "Entrevista. O Amazonas preservou a floresta e destruiu a cidade". Revista de História, Rio de Janeiro, 6 maio 2009. Disponível em: <http://www.revistadehistoria.com.br/secao/ entrevista/milton-hatoum $>$. Acesso em: 19 jun. 2016.

7. PAMuk, Orhan. The Naive and the Sentimental Novelist. Trad. Nazim Dikbaş. Cambridge: Harvard University Press, 2010, p. 80. 
"É uma pintura de Domenico de Angelis: A glorificação das belas-artes na Amazônia. Imitação da que ele fez para o salão nobre de nosso teatro".

A reprodução do afresco neoclássico retratava aquela feita no teto no Salão Nobre do Teatro Amazonas. O Salão Nobre foi concebido como um espaço social exclusivo, cujo acesso era permitido apenas para os convidados mais ilustres, durante os longos intervalos das apresentações. A intenção ali era criar uma identidade de elite e demonstrar deferência, na região, para com a arte europeia.

Além de ser uma demonstração de status, a disposição dos itens na sala de visitas de Jano atua metonimicamente como um manifesto sobre a sua Manaus: uma cidade com laços estreitos entre os militares, empresários e políticos, em que os recursos extraídos ao longo do rio Amazonas trazem grande riqueza para a elite e onde a arte considerada louvável é a que foi santificada décadas antes. No entanto, a versão de Manaus a que Jano se apega está desaparecendo em 1965. Quando Jano se refere ao Teatro Amazonas como nosso, essa identidade coletiva compreende os escalóes superiores da sociedade manauara a que Jano ainda pertence. No entanto, ele despenca dessa classificação quando falha ao aceitar as mudanças na cultura empresarial, que se afasta do clientelismo, apadrinhamento e extração de recursos para a modernização conservadora que envolve a colaboração com empresas multinacionais. Neste ponto do romance, Jano (um apelido que é o mesmo nome do deus romano das transições e do comércio) se encaixa confortavelmente dentro das convicções e prioridades do regime militar, ainda bem pouco específicas. Em breve, seus amigos na política irão traí-lo, em parte devido à incapacidade dele para ajustar o seu comércio de juta às demandas do mercado. A descrição do salão da mansão dos Mattoso como uma exposição estabelecida de artigos de luxo e as referências à extração de recursos chamam a atenção para o desejo de Jano de congelar o tempo no momento de maior prestígio de sua família. Porém, as descrições no romance do tratamento duro dispensado aos colhedores de juta que trabalham para a família Mattoso na década de 1960 mostram uma continuidade preocupante da exploração do boom da borracha na Amazônia (1870-1910).

Após o passeio pela casa, Macau - o chofer da família Mattoso - conduz Jano e Lavo pelo centro de Manaus, onde eles passam por edifícios neoclássicos construídos durante a virada do século. Essa viagem está ligada à aliança de Jano com o centro da

8. hatoum, Milton. Cinzas do Norte. São Paulo: Companhia das Letras, 2005, p. 31. 
cidade, que é o núcleo de poder e riqueza. O narrador traça a trajetória específica da jornada, um caminho sinuoso para o escritório de Jano: começa na mansão, passa pelo Palácio da Justiça, segue pela avenida Epaminondas até a praça General Osório e, em seguida, continua, passando pela praça Pedro II, pela avenida Sete de Setembro, até o fim da avenida Marechal Deodoro. Essa lista aparentemente exaustiva de marcadores geográficos matiza o romance em vários níveis.

Em primeiro lugar, os nomes das ruas seguem a tradição de honrar figuras militares específicas, políticos nacionais fundamentais e momentos importantes da independência nacional. Evocam a admiração de Jano por homens de destaque e oficiais militares de destaque do passado e do presente. Seu próprio nome, afinal, é Trajano, o nome de um imperador romano. Em contraste, Mundo, o suposto filho de Jano, resiste a figuras de autoridade evitando completamente as ruas, optando por viajar através de igarapés e atalhos e se esconder debaixo da terra ou em uma árvore. Assim, o contraste entre seguir a tradição e libertar-se dela é reiterado espacialmente na maneira com que as personagens se movem dentro da cidade.

Em segundo lugar, os pontos pelos quais eles passam ecoam os desejos de Jano e as transgressões de Mundo. Jano deseja ver Mundo demonstrando interesse em mulheres e parando de perder tempo na companhia de Arana, um artista local. No escritório de Jano, o destino final, Jano oferece a Lavo uma grande soma de dinheiro em troca de persuadir Mundo a viver como Jano deseja. A viagem sinuosa para o escritório passa por todos os pontos da cidade que Jano frequenta no romance: a igreja de São Sebastião, o hospital Beneficência Portuguesa, a igreja da Matriz, sua mansão neoclássica, o Colégio Militar, as docas e seu escritório do outro lado da rua a partir da Alfândega. Esses locais - através tanto de sua austeridade neoclássica, quanto de sua função - restabelecem as expectativas (heteronormativas, orientadas para os negócios da família e pró-regime militar) que Jano tem de Mundo.

Em terceiro e último lugar, as referências a uma praça pública em estilo belle époque (praça Pedro II) e a um edifício neoclássico (Palácio da Justiça) simplificam para o leitor a visualização do tipo de urbanismo no centro de Manaus que Jano venera por sua beleza clássica e evocação de lei e ordem. A referência à velha praça General Osório, um espaço público usado para treinamento militar, é uma sinédoque para as praças públicas da belle époque que ainda dominavam a cidade na década de 1960, mas que foram destruídas durante a urbanização dos anos 1970 e 1980. J. Hillis Miller argumenta que muitos romances assumem que seu leitor terá tanto conhecimento sobre o lugar citado quanto sobre os marcadores geográficos - como ruas específicas e edifícios 
- elipticamente transmitirão significado. ${ }^{9}$ Parte do jogo espacial em Cinzas do Norte envolve interpretar as conotações de locais históricos, bem como detectar o que ainda existe e o que foi arrasado na corrida da década de 1970 para transformar a cidade em um polo industrial modernizado.

Doreen Massey entende espaço como "a esfera de uma simultaneidade dinâmica, constantemente desconectada por recém-chegados, sempre à espera de ser determinada (e, portanto, sempre indeterminada) pela construção de novas relações". ${ }^{10}$ Massey derruba as concepções estereotípicas do espaço como estático, firme e representável, entendendo-o, em vez disso, como o produto de uma série de negociações. As negociações que continuamente transformam o centro de Manaus estão bem claras quando a mansão Mattoso é destruída em Cinzas do Norte.

Em 1967, sob o governo do presidente-general Castelo Branco, a Zona Franca de Manaus expandiu-se significativamente. Cerca de duzentas empresas foram transferidas para a Zona Franca nos anos subsequentes, e isso atraiu um afluxo maciço de migrantes em busca de trabalho e exigiu reformas urbanas significativas na década de 1970. Em 1960, Manaus abrigava $25 \%$ da população do estado, mas, em 1980, detinha quase metade de sua população. Como observa Janet Chernela, "em menos de duas décadas, quase todas as facetas da vida social, cultural e econômica da cidade foram alteradas quando relações capitalistas substituíram as anteriores, patrimoniais". ${ }^{11}$ Cinzas do Norte registra essas transformações com o fim do negócio de Jano e a demolição da mansão da família Mattoso para erigir um grande hotel, o último descrito por Lavo na seguinte passagem:

O estuque caiu e se espatifou como uma casca de ovo; no assoalho se espalharam cacos de musas, cavaletes e liras, que os homens varriam, ensacavam e jogavam no jardim cheio de entulho; pedi a um demolidor um pedaço da pintura com o desenho de um pincel: "Pode levar todo esse lixo", disse ele, tossindo na poeira. ${ }^{12}$

9. Miller, J. Hillis. Topographies. Stanford: Stanford University Press, 1995, p. 105.

10. MASSEy, Doreen. For Space. London: Sage, 2005, p. 107.

11. Chernela, Janet M. "Missionary Activity and Indian Labor in the Upper Rio Negro of Brazil, 168o1980: A Historical-Ecological Approach”. In BALÉE, W. L. (Org.). Advances in Historical Ecology. New York: Columbia University Press, 1998, pp. 313-33, p. 327.

12. натоuм, Milton. Cinzas do Norte, cit., pp. 224-5. 
No final de 1970, o afresco pintado no teto da mansão Mattoso torna-se lixo, enquanto a arte experimental de Mundo torna-se valiosa. David Harvey descreve as transformações do ambiente construído das cidades como "uma luta perpétua em que o capital constrói uma paisagem física adequada à sua própria condição em um momento particular no tempo, só para precisar destruí-la, geralmente, no decurso de uma crise, em um ponto posterior no tempo" ${ }^{13}$ A crítica de Harvey é aplicável a esta cena. A passagem de uma economia de extração de recursos para uma economia de manufatura modifica o tecido urbano de Manaus, mas a dificuldade continua. As tensões presentes no romance pairam, esperando para serem resolvidas: a velha Manaus e seus patriarcas permanecem em um impasse frente à modernização conservadora.

Para concluir esta seção sobre espaços da belle époque de Manaus, as observações de Edward Soja sobre a produção do espaço são ilustrativas. Ele argumenta que "o espaço em si pode ser primordialmente oferecido, mas a organização e significado do espaço são produtos de tradução social, da transformação e da experiência". ${ }^{14}$ Romances que se concentram em determinados lugares geográficos estão engajados nesse processo de construção de significado. Cinzas do Norte tem o poder de transformar a percepção dos leitores quanto a Manaus. Na verdade, frequentemente o primeiro e único "contato" dos leitores com a capital do Amazonas se dará através da ficção de Hatoum. A Manaus do romance é um lugar em que Mundo ressignifica a triunfante arte pública, a arquitetura neoclássica espelha a austeridade e o peso da imponência de Jano, e estruturas físicas são vulneráveis à demolição dentro de um processo de contínua transformação urbana.

Além de retratar o centro neoclássico, Cinzas do Norte utiliza a Cidade Flutuante para envolver uma realidade histórica e para melhorar os componentes imaginários da narrativa. A Cidade Flutuante foi um bairro real em Manaus. Em 1964, havia mais de 2 mil edifícios flutuantes no rio Negro perto do Mercado Central, no centro de Manaus. Apesar de, em décadas anteriores, edifícios flutuantes nessa área terem uso comercial, a chamada Cidade Flutuante expandiu-se significativamente no começo da década de 1960 como uma área residencial para os pobres urbanos. No seu auge, abrigava $12 \mathrm{mil}$

13. Harvey, David. "The Urban Process under Capitalism: A Framework for Analysis”. In: bridge, G.; watson, S. (Orgs.). The Blackwell City Reader. Malden: Blackwell, 2002, pp. 116-124, p. 120.

14. SOJA, Edward W. Postmodern Geographies: The Reassertion of Space in Critical Social Theory. New York: Verso, 1989, pp. 79-80. 
habitantes. ${ }^{15}$ Na gestão do governador Arthur Cézar Ferreira Reis, em 1965, o governo começou a desmontar a Cidade Flutuante, como parte da modernização conservadora do regime militar e da implantação da Zona Franca de Manaus. Até 1966, a Cidade Flutuante já havia sido destruída. ${ }^{16}$

Em Cinzas do Norte, a Cidade Flutuante pode ser entendida, por um lado, como uma abordagem sobre o espaço que é menos austera do que a arquitetura neoclássica da belle époque, abrindo, assim, caminho para a espontaneidade e para a criação. Por outro lado, a Cidade Flutuante está ligada à violência e às lutas pelo poder que produzem espaço. Essas concepções da Cidade Flutuante tornam-se significativas de duas maneiras: 1) a maneira evasiva com que Mundo circula através de Manaus e 2) o envolvimento artístico de Mundo com o despejo dos moradores da Cidade Flutuante e com outras práticas espaciais preocupantes em Manaus.

Como postula bell hooks, "para transgredir devo ultrapassar os limites do passado, devo abrir caminho e seguir em frente [...]. E somos ensinados repetidamente que a única maneira de permanecer seguro é permanecer dentro de limites fixos. $\mathrm{Na}$ maioria das vezes, são os laços da família, comunidade, nação". ${ }^{17}$ A Bildung de Mundo é uma longa e árdua transgressão, que desafia os limites estabelecidos pela família, comunidade e regime militar no Brasil. Além disso, alinhada com as teorizações de Michel de Certeau - a maneira como Mundo se move através de Manaus enfrenta os limites, até mesmo as ruas, que tentam limitar sua mobilidade. Por exemplo, em uma cena que se passa em 1965, Mundo desliza para fora da estrada na direção de uma quebrada, atravessa um beco e um terreno baldio, chega à rampa lamacenta de um estaleiro e continua sua viagem de canoa.

Ele então rema ao longo do rio Negro, até o igarapé do Franco, chegando a um canal onde atraca em uma pequena ilha que abriga o ateliê e a casa de seu mentor, Arana. Essa cena começa no bairro Aparecida, onde Lavo segue Mundo e observa a atração deste último pelos submundos de Manaus, a boemia, a depravação, esconderijos

15. BARATA SOUZA, Leno José. “A ‘Cidade Flutuante’ de Manaus: rediscutindo conceitos”. Aedos: Revista do Corpo Discente do PPG-História da UFRGS, Porto Alegre, v. 6, n. 3, pp. 148-165, 2010. Disponível em: <http://www.seer.ufrgs.br/aedos/article/view/12507>. Acesso em: 20 abr. 2016, p. 152.

16. Id., p. 151. A Cidade Flutuante e sua destruição também são significativas para o romance Dois irmãos de Hatoum (2000). Marcos geográficos e práticas espaciais compartilhados em Manaus (e personagens que reaparecem em mais de um texto) interligam as obras de ficção de Hatoum.

17. HоOKs, bell. “Transgress”. Paragraph, Edinburgh, v. 17, n. 3, pp. 270-1, 1994, p. 270. 
e atalhos. Lavo alinhava a cena com as interações de Mundo e com reflexões sobre uma família ameríndia desabrigada vivendo perto de uma cerca enferrujada em Aparecida, reiterando, assim, o desejo de Mundo de ver além da vista de cartão-postal de Manaus.

Essa jornada estabelece como Mundo e Jano lidam de formas diferentes com Manaus. Jano permanece dentro das praças bem cuidadas e edifícios imponentes e abre sua própria mansão para os encontros sociais com seus iguais da alta sociedade. Em contraste, Mundo evita os locais de reunião de sua classe social e se esforça para esconder seu paradeiro de Jano. Ironicamente, essa trilha labiríntica destinada a iludir Jano termina no seu pai biológico: Arana (um mistério revelado apenas no final do romance).

Novo Eldorado, o nome de fantasia de um complexo de habitação pública em Cinzas do Norte, sugere a lendária cidade encantada do rei dourado, pela qual houve uma busca que produziu os mapas iniciais do interior da Guiana. ${ }^{18}$ Assim, a busca por uma cidade imaginária levou um lugar real a ser mais bem compreendido, que exemplifica o desafio de separar o real e o imaginário em nossas interpretações do espaço. O nome do conjunto de habitação público também é paralelo ao massacre de Eldorado dos Carajás, no sul do Pará, em 1996, em que policiais militares atiraram e mataram dezenove agricultores sem terra que protestavam contra os atrasos na desapropriação de terras improdutivas. Com tal alusão, o romance reflete sobre a violência relacionada com a alocação de espaço.

Até agora, o presente ensaio tem incidido sobre a parte sul de Manaus, que inclui o centro, mas justaposições entre esta área sul e bairros menos abastados mais ao norte e oeste são cruciais para a trama. Duas áreas que aparecem com frequência são o inventado Novo Eldorado (semelhante ao conjunto de habitação Castelo Branco no bairro Parque Dez, onde Hatoum viveu) e o inventado Morro da Catita, perto ou dentro dos limites do real bairro São Jorge, a noroeste do centro da cidade. No período em que se passa o romance, Novo Eldorado e Morro da Catita marcam os limites exteriores da cidade. Servem para desafogar a expansão impressionante de Manaus que, desde 1950, mais do que quadruplicou a sua área geográfica.

Henri Lefebvre argumenta que os conflitos sociopolíticos, porque têm lugar no espaço, são necessariamente conflitos de espaço, e Cinzas do Norte apresenta como moralmente inconcebível a expulsão continuada dos moradores pobres do centro da

18. BURnetT, D. Graham. Masters of All They Surveyed: Exploration, Geography, and a British El Dorado. Chicago: University of Chicago Press, 200o, pp. 25-6. 
cidade. ${ }^{19}$ No romance e na realidade, o governo da cidade forçou os moradores do rio a passarem para o outro lado de Manaus, para uma área recentemente desmatada onde casas haviam sido construídas. Mundo visita este novo bairro, Novo Eldorado, e testemunha a violência espacial ligada à remoção de favelas: "[Mundo] visitara as casinhas inacabadas do Novo Eldorado, andara pelas ruas enlameadas. Casinhas sem fossa, um fedor medonho. Os moradores reclamavam: tinham que pagar para morar mal, longe do centro, longe de tudo... Queriam voltar para perto do rio". ${ }^{20}$ Essas abjetas condições de vida inspiraram Mundo a fazer uma peça específica para o lugar, uma instalação artística composta de oitenta cruzes de madeira instaladas na frente de cada casa de Novo Eldorado, e a cobrir de panos drapeados os galhos de uma seringueira no centro do aglomerado de habitação, a única árvore poupada na demolição. ${ }^{21}$ Sua arte fúnebre salienta que o conjunto de habitação é tão precário que é mais adequado para a morte do que para a vida, em ambos os contextos, social e ambiental. O romance estabelece paralelos entre a restrição espacial experimentada em Manaus por Mundo e pelos antigos moradores da Cidade Flutuante. "Os moradores do Novo Eldorado eram prisioneiros em sua própria cidade”, observa Mundo, sentindo como ele e sua circulação através de Manaus têm sido restringidos de forma autoritária, ligando assim a história pessoal do romance com as transformações espaciais reais ocorridas em Manaus. ${ }^{22}$

No entanto, algumas personagens do romance não concordam com a interpretação de Mundo desse espaço. O gabinete do prefeito e a polícia queimam a instalação, em um esforço para destruir qualquer traço de crítica visual das práticas sociais e espaciais do regime. A transgressão de Mundo é grave. Para escapar da lei e da ira de seu pai, ele passa mais de um mês escondido no Morro da Catita, ao lado do bairro onde a mãe de Mundo cresceu. Sugestivamente, a evasão de Mundo o coloca mais próximo do local empobrecido onde sua mãe lutou muito para nunca ter que voltar. Rejeitando a mobilidade ascendente que a mãe tornou possível para ele, Mundo abandona a riqueza e o

19. Lefebvre, Henri. The Production of Space. Trad. Donald Nicholson-Smith. Malden: Blackwell, 1991, p. 365 .

20. hatoum, Milton. Cinzas do Norte, cit., p. 148.

21. Para uma análise de como as formas desfiguradas (particularmente as grotescas e zoomórficas) figuram na arte de Mundo dentro do romance, ver: SARMEnTo-PANTOJA, Tânia. "Efeitos de grotesco em Cinzas do Norte, de Milton Hatoum”. Anais do Silel, Uberlândia, v. 2, n. 2, 2011. Disponível em: <www.ileel.ufu.br/anaisdosilel/pt/arquivos/silel2011/2191.pdf>. Acesso em: 16 jun. 2015.

22. натоum, Milton. Cinzas do Norte, cit., p. 148. 
status do centro da cidade, preferindo contestar as práticas espaciais do regime militar através de sua arte.

Em um romance em que quase todas as personagens concordam com o regime militar, a instalação de arte é um dos poucos protestos públicos. Contudo, o romance não caracteriza a intervenção de Mundo como heroísmo, apresentando-a, ao contrário, como um risco, desobediência e o ato idealista de um sonhador. Quando Lavo pergunta a uma residente sobre a instalação de arte de Mundo, ela responde: "A fumaceira? [...] Depois o povo do bairro queimou as cruzes e a árvore". ${ }^{23}$ Ela não vê uma ligação entre a instalação e sua própria vida. Para ela, o único valor da obra de arte é utilitário: ela fornece lenha para sua comunidade.

Em uma cena que envolve temporalidade confusa e intenções desperdiçadas, Jano, observando a instalação de Mundo, pergunta: "Por que tinham construído as casas num cemitério? onde estava o trabalho do filho?". ${ }^{24}$ Assim, a obra de arte atinge o efeito desejado de fazer o espectador enxergar o espaço de forma diferente, ainda que Jano não reconheça a arte como arte. Essa inadvertida observação de uma obra de arte é o mais próximo a que as duas personagens vão chegar de um momento de comunhão.

Para o diretor da academia militar, a instalação de arte ameaça a ordem civil: "Como podia? Um estudante incitar todo um bairro contra o prefeito, um oficial das Forças Armadas!”. ${ }^{5}$ O jornal deprecia Mundo e os moradores de Novo Eldorado em sua cobertura da peça. Mundo é descrito como "um filho rebelde, estudante fracassado e dândi fardado que queria fazer arte contemporânea num bairro de gente pobre, onde quase todos são analfabetos" ${ }^{26} \mathrm{O}$ jornal não reconhece a ligação entre o analfabetismo e o tipo de marginalização que Mundo critica. Jano, o militar e as reações do jornal acentuam como a família, o Estado e a mídia tinham definido concepções estritas sobre práticas espaciais adequadas, que Mundo transgrediu. A inclusão de várias perspectivas de espaço enfatiza até que ponto as representações do espaço estão ligadas a disputas sobre como um determinado lugar deve ser interpretado.

Mundo acredita que "todo ser humano em qualquer momento de sua vida devia ter algum lugar aonde ir”, um sentimento que conecta sua própria sensação de desen-

\footnotetext{
23. Id., p. 178 .

24. Id., p. 183 .

25. Id., p. 185 .

26. Id., p. 177 .
} 
raizamento com uma posição sociopolítica sobre o direito à habitação. ${ }^{27}$ Suas previsões sobre Novo Eldorado ser um lugar impróprio para viver são posteriormente confirmadas no contexto da década de 1980, quando tomamos conhecimento de que os residentes de Novo Eldorado (incluindo Macau) contraíram leishmaniose, uma doença que é potencializada pelo desmatamento, desnutrição e pobreza. Além disso, o lugar onde Mundo tinha erguido sua instalação mais de uma década antes se transformou, em 1980, em um campo abandonado coberto de mato com um cartaz oxidado onde se lê: "Praça Coronel Aquiles Zanda". A praça foi batizada em homenagem ao prefeito e se destaca como um lembrete visual de que a construção de uma praça pública e outros serviços públicos foram promessas não cumpridas do gabinete do prefeito. A instalação de Mundo erguida sobre uma área desmatada de terra e a visita de Lavo àquele lugar obrigam o leitor a refletir sobre o espaço. A praça pública não construída simboliza o fracasso do conjunto habitacional que foi erguido para os residentes, não pelos residentes, com pouca atenção dada às necessidades ou aos desejos deles, mesmo aqueles tão simples quanto um espaço sombreado.

O romance apresenta Manaus e a Amazônia não só como lugares tangíveis, mas também como representações artísticas que correm o risco de serem estereotipadas e de interpretarem erroneamente práticas espaciais e sociais violentas. Por exemplo, Arana, de forma oportunista, vende pinturas e esculturas de Manaus que retratam a cidade como querem que a cidade seja: o habitat de nobres selvagens, papagaios, arranha-céus, ópera, desmatamento ou qualquer combinação desses fatores que se deseje ou que esteja na moda. Uma das pinturas de Arana retrata um grupo de ameríndios estereotipicamente vestidos assistindo a uma ópera no Teatro Amazonas. Outra, adequada aos interesses da contracultura brasileira da década de 1960, lida com desmatamento e violência na floresta amazônica. No fim da década de 1970, Lavo vê uma das pinturas de Arana no escritório de um empresário, e a peça reitera o ethos da Zona Franca de Manaus: "um painel pintado com araras. Imensas, sobrevoavam um amontoado de torres de vidro e concreto no horizonte desmatado. A visão alucinada e grotesca da floresta, e talvez do futuro" ${ }^{28}$ Fredric Jameson refere-se à condição pós-natural em que as características geográficas de uma região têm sido "sistematicamente eclipsadas do mundo objetivo e das relações sociais de uma sociedade cuja dominação tendencial sobre seu Outro (o

27. Id., p. 308.

28. Id., p. 264. 
não humano ou o ex-natural) é mais completa do que em qualquer outro momento da história humana". ${ }^{29} \mathrm{Na}$ pintura de Arana, na qual a dominação é quase completa, a única característica geográfica remanescente da Amazônia são os pássaros. Como diz Allison Leão, Arana percebe que representações estereotipadas e estáticas apelam aos desejos dos consumidores, ao passo que Mundo busca significações abertas, dinamismo e desvanecimento (mesmo da arte que desaparece) em sua abordagem da Amazônia. ${ }^{30}$

Mundo tenta fugir da Manaus de Jano e também da representação de Manaus de Arana, andando a pé pela cidade e fazendo de sua arte uma forma de resistência. A representação artística da cidade e a cidade real se intercalam. Como Victor Burgin diz: "A cidade em nossa experiência real é ao mesmo tempo um ambiente físico que existe de verdade, $e$ uma cidade em um romance, um filme, uma fotografia, uma cidade vista na televisão, uma cidade de história em quadrinhos, uma cidade de um gráfico de pizza, e assim por diante". ${ }^{31}$ Os ambientes urbanos real e inventado colidem. Cinzas do Norte é em si mesma uma representação artística de Manaus preocupada com as representações artísticas daquela cidade. Nesse jogo metarrepresentacional, a ambientação imaginária nos atrai mais profundamente para dentro da trama, e a cidade tangível, num sentido brechtiano, puxa-nos para além dos limites do romance, em direção à política de espaço do mundo real. ${ }^{32}$

Para concluir, Mundo alinha-se com as prioridades da Cidade Flutuante, tanto no sentido sociopolítico quanto no sentido metafórico. Ele resiste a ser espacialmente confinado por definições ou fronteiras rígidas, optando por vagar livremente. No entanto, como a reação da residente de Novo Eldorado à instalação do Mundo deixa claro, há limites para onde e como ele pode se conectar com uma Manaus mais ampla, na qual ressoam as promessas e desafios da arte política do Brasil dos anos 1960 e $1970 .{ }^{33}$

29. Jameson, Fredric. Postmodernism, or, The Cultural Logic of Late Capitalism. Durham, NC: Duke University Press, 1991, p. 170.

30. LEÃo, Allison. "Regionalismo e representação da natureza em Milton Hatoum: contribuição para um (outro) debate”. In: LEÃo, A. (Org.). Amazônia: literatura e cultura, cit., pp. 61-89, p. 83.

31. Burgin, Victor. In/Different Spaces: Place and Memory in Visual Culture. Berkeley: University of California Press, 1996, p. 28.

32. BRECHT, Bertolt. Brecht on Theatre: The Development of an Aesthetic. Trad. John Willett. Ed. John Willett. New York: Hill and Wang, 1964, p. 91.

33. Sobre o engajamento político da arte no Brasil nos anos 1960 e 1970, ver: RIDENTI, Marcelo. Em busca do povo brasileiro: artistas da revolução, do CPC à era da TV. Rio de Janeiro: Record. 2000. 
Cinzas do Norte convida-nos a demorar o nosso olhar em Manaus e, se o fizermos, os nossos esforços serão recompensados. Descobrimos interação entre a cidade material, representações artísticas da mesma, e práticas espaciais das personagens em Manaus. Essa interação revela conexões entre urbanismo, mobilidade e violência tanto dentro da esfera da cidade imaginária do romance quanto dentro da Manaus material, histórica. Cinzas do Norte, com a sua cuidadosa apresentação de um lugar tangível, oferece uma elegia a uma Manaus dos anos 1960 que não existe mais. No entanto, esta elegia não é redutiva. Poderíamos esperar que o romance retratasse Manaus de forma inteligível, estática e unificada, mas, em vez disso, nos é apresentada a visão caleidoscópica de um espaço disputado e contingente. Como Hatoum alega, "a poesia e a prosa são formas de resistir à banalização e ao conformismo". ${ }^{34}$ Cinzas do Norte descreve Manaus de uma forma que resiste à banalidade e ao conformismo típicos das representações comuns. Os leitores se empenham para entender como Manaus é significativa para o mundo imaginário do romance e para além dele e, nesse processo, enxergam a cidade novamente.

Sophia Beal é Professora da University of Minnesota.

34. hatoum, Milton. "Entrevista com Milton Hatoum". Concedida a Francismar Barreto, Maria Isabel Edom Pires, Mônica Kalil Pires e Sara Freire Simões. Estudos de Literatura Brasileira Contemporânea, Brasília, n. 28, pp. 141-7, 2006. Disponível em: <http://periodicos.unb.br/index.php/estudos/article/ view/2102/1669>. Acesso em: 20 jun. 2016. 